\title{
Development of a progressive green university campus maturity assessment tool and framework for Malaysian universities
}

\author{
Christy P. Gomez ${ }^{1, *}$, and $N g$ Yin Yin ${ }^{2}$ \\ ${ }^{1}$ Assoc. Prof. Universiti Tun Hussein Onn Malaysia, 86400 Batu Pahat, Johor, Malaysia \\ ${ }^{2}$ Researcher, Universiti Tun Hussein Onn Malaysia, 86400 Batu Pahat, Johor, Malaysia
}

\begin{abstract}
Globally there is an increasing focus on green and sustainability practice within university campuses. However, this is not the case in Malaysia. This paper proposes a green maturity framework for Malaysian universities based on having identified criteria for achieving greener university campus relevant to Malaysian context. Additionally, obstacles faced by universities in the development of green university campuses are identified. Two sets of questionnaire survey forms were used to collect data. The questionnaire for identifying green campus rating criteria to form the Green University Campus Maturity (GUCM) Assessment Tool based on 9 categories was distributed to GBI facilitators. The criteria's weightage for scoring was based on the average level of importance as decided by the respondents. The questionnaire for identifying the obstacles faced by universities (Areas to Address) was categorized into economic, organizational and social/behavioural/technical and distributed to the respective Department of Sustainable Development staff in public universities. Lack of relevant managerial experience in implementing green university projects and lack of funding were found to be the main obstacles in the development of green university campus. The GUCM Assessment Tool alongside the Areas to Address can be used as a county-specific GUCM framework for achieving progressive sustainability attainment by Malaysian universities.
\end{abstract}

\section{Introduction}

There are some confusion with regards to the term "green" and "sustainability". From reviewing extant research literature on the subject of sustainability of university campuses, it is clear that it is covered under both the categories of "green" and "sustainability". Following [1], the view taken in this paper is that the green concept is mainly focused on environmental improvement whereas sustainability is focused in a much wider sense on the triple bottom line, which are economy, environment, and social. Thus, the aspect of people, process and place tend to play a significant role in building a sustainable campus. Hence, the concept of green here is used in a wider sense to cover the elements of the Triple Bottom Line in terms of social, economic and environmental, as well as that of education.

In order to maintain Malaysia's aspiration as a low carbon, sustainable building and infrastructure hub [2], the Construction Industry Development Board (CIDB) has formulated The Malaysian Construction Industry Transformation Programme (CITP), which amongst other major aspirations, aims to achieve sustainability by implementing environmentally sustainable construction practices specifically aims to reduce irresponsible discarding of construction waste as well as damage and repair expenditure to start with and pursue the aim of a sustainable future. However, currently this aspiration of becoming a low carbon, sustainable and infrastructure hub is being addressed in pockets and is fraught with various challenges. One major challenge is the inability to secure and sustain the commitment amongst the various sectors of the construction industry, the relevant authorities and key building and infrastructure stakeholders towards this end. There have been many strategies and approaches that have been implemented, both by governments and private entities, which is seeing considerable progress in some major areas of concern; such as improving energy efficiency. One such approach is through the use of green assessment or rating tools, which targets specific aspects of the built environment. These strategies and approaches within the sustainability agenda is seen as transitioning away from unsustainable practices. Often initially this transition takes place by focusing on the "low hanging fruits" that demands less effort.

The effort towards more sustainable development is being jointly undertaken by the public and private sector in Malaysia. This effort seems to be framed very much within different place types - such as different types of buildings, townships and of recent schools, colleges and universities. Universities in general have begun instituting improvement strategies and making commitments towards sustainable practice, although with varying degrees of indulgence. Noticeably the level of importance placed on sustainability is being influenced greatly by the particular countries' sector of the built environment's commitment towards the

* Corresponding author: cpgomez21@gmail.com 
sustainability agenda. The effort of tackling the sustainability agenda for the education entities such as universities, additionally places emphasis on building a community that is enculturatd in sustainability practice.

Universities play a fundamental role in society, in the formation of future generations and in the preparation of future professionals, with a view to transitioning toward sustainability. According to [3], the need to consider sustainability in academic institutions is twofold. They can be considered as "small cities" which may have heavy impact on the environment due to their activities, movement of goods and persons inside campuses. Universities can be seen as complex buildings, involving transportation, water and materials consumption, energy and electricity consumption.

It is noted by [4] that universities are lagging behind companies in helping society become more sustainable. However, of recent greater emphasis is being placed to redress this matter. This is reflected in the the increasing commitment by universities globally towards addressing sustainability performance, as noted by the increasing number of higher education signatories to the United Nations' Higher Education Sustainability Initiative. A notable outcome of the work undertaken is the publication of the Greening Universities Toolkit [5]. Additionally, there are increasing number of universities that have taken up assessments for green campus.

This paper sets out to identify the relative importance of various criteria for evaluating green university campus attainment level in Malaysia. The results also serve to structure a green maturity level framework (maturity index) for assessing Malaysian university campuses. Additionally, the obstacles related to the development of green campus are identified to enable the structuring of a more holistic Green University Campus Maturity (GUCM) framework that can be used as a tool by practitioners.

\subsection{Background of study}

The green or sustainable university initiative has many drivers. Key amongst these is green campus assessment. In general sustainability assessment is usually conducted for supporting decision making and policy development and not just for the purpose of image and status. As noted by [6], assessing sustainability is increasingly becoming common practice in product, policy, and institutional appraisals.

With respect to global green and sustainability rating in university campuses, UI GreenMetric World Universities Ranking is the first attempt as a rating tool and provides world ranking of universities' for sustainable behaviour [7]. The ranking of green universities is based on a rating of selected sustainability criteria. Some of the main categories of the criteria are: infrastructure, energy, waste, water and transportation. The criteria are related to the operation of the university and the influences of environmental impact of the university in the long term.

This work subcribes to the view that the sustainability or green focus be emphasised on universities as a whole [8]. A whole-of-university approach recognises that besides the general approach taken towards sustainability, all functions of the institution can benefit from sharing knowledge and it can as well influence students learning experience towards sustainable development.

\subsection{Research gap and issues}

It is pointed out by [9] that although, many Malaysian universities have proposed different strategies to implement sustainable practice, however they note that the green concept and sustainability practice needs to improve. The implementation of the green university concept in Malaysia still ranks low when compared with other countries [10]. Whilst [11] proposed a green potential rating tool for universities that is focused on improving the sustainable features of only university buildings as part of a refurbishment initiative.

In Malaysia, universities with a high focus on green and sustainability concept are lacking. In terms of green university campus, the ranking of Malaysian green university campus is low compared with other countries such as Canada, United Kingdom, and America [10]. Universiti Putra Malaysia (UPM) has the highest ranking amongst the universities in Malaysia based on 2015 ranking. It is ranked 17 th based on the participating universities in the UI GreenMetric Ranking [12].

The authors are convinced that although increasing work is being done globally on green campus rating tools, there needs to be a country-specific rating tool that is more responsive to its own climatic and development status (emerging or developed). Also to be tailored specifically to each country's building by-laws and standards, cultural relevance and social needs.

\section{The green initiative}

The green or sustainability initiative within the construction industry, received greater attention following the Brundlandt Report in 1987. A notable development towards sustainable development was the evolvement of green building rating systems which began formally in the 1990s. Not surprisingly, now there are a plethora of such rating tools and systems such as HK-BEAM, LEED, GBI Tool, CASBEE, BREEAM, and many more. These rating systems have expanded to include even townships. Green rating systems for university campuses, however are relatively new.

The green university campus is viewed as a higher educational institution that involves and promotes on a global level, the minimization of negative environmental, economic, societal and health effects in use of resources to fulfil the functions of teaching, research, outreach and partnership, and stewardship in ways to help the development of green university concept [13]. From a global perspective there are two well established green university campus rating tools, namely UI GreenMetric ${ }^{\mathrm{TM}}$ and STARS ${ }^{\mathrm{TM}}$. 


\subsection{Green university campus rating tools - UI GreenMetric and STARS}

UI GreenMetric and STARS generally evaluate universities according to the specific criteria and indicators that are suitable for safeguarding the environment of higher educational institutions. Universitas Indonesia took the initiative to develop an online green university ranking for world universities in 2010 [10]. Initially the ranking was planned to serve as an awareness raising mechanism. There are six main criteria of UI GreenMetric World University Ranking which includes environmental setting and infrastructure, energy and climate change, waste, water, transportation and education. Before 2012, UI GreenMetric had only five main criteria which did not include education. However, the education criterion was added in 2013.

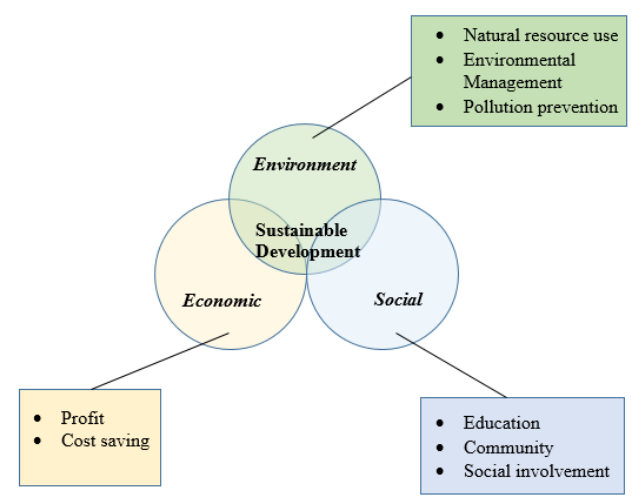

Fig. 1. Sustainable development model in UI GreenMetric (source: [14])

The UI GreenMetric ${ }^{\mathrm{TM}}$ World University ranking system is based on a broad philosophy that encompasses the conceptual framework of Environment, Economic, and Social which takes into consideration the importance of green and sustainability universities concept [14] as shown in Fig.1.

One other major green university rating tool is STARS. The Sustainability Tracking, Assessment \& Rating System ${ }^{\mathrm{TM}}$ (STARS) is a self-reporting framework for colleges and universities to measure the sustainability performance. In addition, STARS encompasses long term sustainability goals for high-achieving institutions as well as entry points of recognition for institutions that are taking first steps toward sustainability. STARS also takes several categories of criteria as the sustainable institutions priority areas. Thus, there are five main criteria: Academics (AC), Operations (OP), Engagement (EN), Planning \& Administration (PA), and Innovation \& Leadership (IN) [15]. STARS was initially developed in large part by reviewing campus sustainability assessments, sustainability reports from businesses, and other sustainability rating and ranking systems [16].

\subsection{Malaysian green building rating tools - Green Building Index (GBI)}

Malaysia has a few green building rating tools which differ slightly: GBI, PH, JKR and GreenRE. However, the most popular green building rating tool system is the Green Building Index (GBI) set of rating tools. GBI is developed specifically for the Malaysian tropical weather, environmental and developmental context, cultural and social needs [17].

Since the focus of the research was to develop a country-specific green university campus rating tool, the GBI rating tools of Non-Residential New Construction (NRNC) and Non-Residential Existing Building (NREB) were specifically identified as having criteria that were more relevant for the intended purposes of the research. Here, university buildings are categorised as nonresidential buildings, although, there are instances of student and staff accommodation on campus. The GBI criteria and score matrix is as shown in Table 1.

Table 1. GBI criteria and scoring for non-residential new construction building (source: [18])

\begin{tabular}{|c|l|c|}
\hline No. & Criteria & GBI \\
\hline 1 & Energy Efficiency & 35 \\
\hline 2 & $\begin{array}{l}\text { Indoor Environmental } \\
\text { Quality }\end{array}$ & 21 \\
\hline 3 & $\begin{array}{l}\text { Sustainable Sites Planning } \\
\& \text { Management }\end{array}$ & 16 \\
\hline 4 & Materials \& Resources & 11 \\
\hline 5 & Water Efficiency & 10 \\
\hline 6 & Innovation & 7 \\
\hline & TOTAL (\%) & 100 \\
\hline
\end{tabular}

The buildings are rated on a point-scoring format and depending on the scores; the buildings are awarded the GBI rating award. Having reviewed the various criteria under the more established rating tools it was decided that the following 9 categories of green or sustainability criteria would be adhered to for the purpose of this research. They are: (i)Setting and Infrastructure (SI) (ii) Energy and Climate Change (EC) (iii) Waste (WS) (iv) Water (WR) (v) Transportation (TR) (vi) Education and Research (ER) (vii) Engagement (EN) (viii) Planning and Administration (PA) and (ix) Innovation and Leadership (IL).

\subsection{Obstacles in achieving green or sustainability status}

Although, some of the main obstacles of green university campus are similar with that of green buildings, there are definitely some differences, especially from the organizational aspect [19]. From literature it is evident that the main economic obstacles for both green building and green university campus are lack of incentives and higher costs.

There are many obstacles that have been identified in the implementation of green building. The obstacles faced in implementing the green building concept are no longer primarily technological and economic. There is growing research that highlights some of the social and psychological obstacles as well [20]. The major 
categories of obstacles that have been identified from literature $[20,21]$ include:
(i) Economic
(ii) Organizational
(iii) Technique
(iv) Technology
(v) Social, and
(vi) Psychological

Interestingly, research on the obstacles on green building and green university seem to have some differences. The psychological category for obstacles is highlighted in green building research literature but not for green university campus.

Based on the comparison of obstacles of green building and obstacles of green university campus, there are definitely differences in the categorization of obstacles. The green university campus obstacles are generally categorized under the following $[19,22]$ :

(i) Economic

(ii) Organizational

(iii) Technique

(iv) Social

Finally, in analysing the various elements of each category and the sub-categories of obstacles for implementation of green building and green university campus, the following categories of obstacles were decided upon as the most appropriate categories for the intended purpose of this research. They are:

(i) Economic

(ii) Organizational

(iii) Social/Behavioural/Technical

\section{Research Methodology}

The quantitative method using the questionnaire data collection technique was applied. Two sets of questionnaires were distributed. The questionnaires for identifying green campus rating criteria to form the Green University Campus Maturity (GUCM) Assesment Tool based on the 9 categories were distributed to registered GBI facilitators. The questionnaire for identifying the obstacles faced by universities (Areas to Address) was categorized into 3 categories and distributed to the respective Department of Sustainable Development staff in public universities using online Google Forms. A total of 60 questionnaires were distributed to GBI facilitators (Questionnaire 1) while 18 questionnaires were distributed to management staff of Malaysian public universities that have a Department of Sustainable Development (Questionnaire 2).

It is recorded in the Malaysian Higher Education Ministry (KPT) website that there are a total of 20 Malaysian public universities in Malaysia. Whilst based on the GBI website, there are a total of 778 GBI facilitators with just 62 active GBI facilitators. A total of 35 questionnaires were received with completed responses from GBI facilitators and 11 questionnaires received from staff of the Department of Sustainable Development of public universities in Malaysia. Both of questionnaires were pilot tested and verified to have the necessary internal consistency (reliability) suitable to be used in this research with a Cronbach's Alpha of 0.924 and 0.971 respectively.

The outcome of the research, which is mainly the GUCM assessment tool, forms the basis in the development of a conceptual GUCM framework that is aligned to the principles of continuous improvement.

\section{Analysis and results}

The average percentage of the overall responses was used to determine the specific level of importance of the specific criteria. This enabled the weightage of criteria to be determined. In each category, the criteria identified as being of basic level was given 1 point, intermediate level criteria was given 2 points, whereas advanced level criteria was given 3 points. The points were then summed up, as graphically represented in Figure 2.

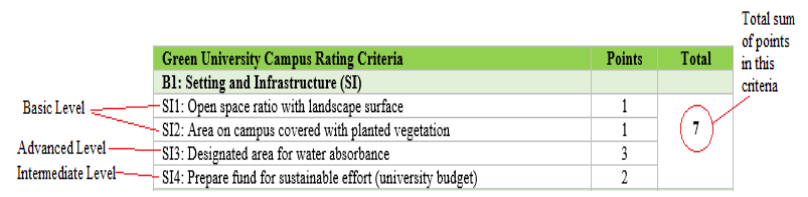

Fig. 2. Weightage for specific criteria

(a) Setting and Infrastructure (SI)

The open space ratio with landscape surface sub-criteria and area on campus covered with planted vegetation was rated Low in terms of importance, with highest percentage response of $62.9 \%$ and $60 \%$ indicating Low respectively. Designated area for water absorbance was rated High, with $80 \%$. Medium level of importance was identified for prepare fund for sustainable effort, which was had a $51.4 \%$ score.

(b) Energy and Climate Change (EC)

Most of the respondents rated as Low level for energy efficient appliances usage and less electricity usage in campus. Besides, majority respondents identified that implementing smart building and renewable energy usage have High impact to enable the green university campus. Medium level for less carbon footprint in campus and Medium level for the university's to have greenhouse emission reduction program.

(c) Waste (WS)

Most of the respondents rated Low Level for reducing the use of paper and plastic in campus and recycling program for university waste. Majority of respondents rated Medium level for the criteria of efficient toxic waste handling. Besides, majority of respondents rated organic waste treatment, organic waste treatment and systemic sewerage disposal as being high in terms of greater impact to enable the green university campus.

(d) Water (WR)

The use of water efficient appliances was rated as being Low in terms of being less important while water conservation was overall rated as Medium level. Water recycling was rated High as well as having treated water for consumption. 
(e) Transportation (TR)

Respondents rated as Low level for the provision of campus bus service. Whilst criteria such as low ratio of vehicles to campus population, bicycle and pedestrian policy and reduction in parking area was rated as Medium level.

(f) Education and Research (ER)

Majority of the respondents rated the students' sustainability organizations and sustainability website as being Low in terms of importance to enable green university campus. However, sustainability courses, sustainability publication, sustainability events and programs and sustainability research was rated as Medium level. However, respondents rated immersive experience, sustainability literacy assessment, and campus as a living laboratory as High level.

\section{(g) Engagement (EN)}

Majority of respondents rated Low level for the outreach campaign. Respondents rated four criteria as Medium in terms of importance, which was outreach materials and publications, employee educators program, staff professional development and continuing education. On the other hand inter-campus collaboration and participation in public policy was rated as being High in terms of importance to enable green university campus.

(h) Planning and Administration (PA)

Majority of respondents rated assessing employee satisfaction as less important to enable the green university campus. Sustainability coordination, sustainability planning, participatory governance, support for underrepresented group and wellness program were rated at Medium level. Whilst, committee on investor responsibility to green criteria and sustainable investment was rated High.

(i) Innovation and Leadership (IL)

There are three criteria in the category of innovation and leadership that were rated as Medium importance to enable green university campus. They are: innovate in sustainability practices, innovate in design and new technology and new and diverse leaderships skills to enable sustainable decision-making. Majority of the respondents rated operationalizing corporate social responsibility as being high in terms of importance to enable the green university campus.

\subsection{Obstacles in development of green university campus in Malaysia}

(a) Economic

Majority of the respondents strongly agreed that lack of funding was the main obstacle that hinders the development of green university campus in Malaysia, followed by higher cost. (b) Organizational

Majority of the respondents strongly agreed that lack of relevant managerial experience in implementing green university projects was the main obstacle under organizational category. Lack of performance indicators to evaluate the success of green university also had high mean value.

(c) Social/Behavioural/Technical

Lack of infrastructure to support implementation of green university campus had a highest mean value among the Social/Behavioural/Technical obstacles. Followed by fundamental knowledge about green university campus.

\section{GUCM framework}

The proposed conceptual GUCM framework to be used by Malaysian universities consists of utilizing the GUCM assessment tool together with the questionnaire for identifying areas to address. Within the operational context of continuous improvement, the universities can formulate a strategy in a progressive and practical manner for actions to prioritize on enhancing their campuses green maturity (see Figure 3 ).

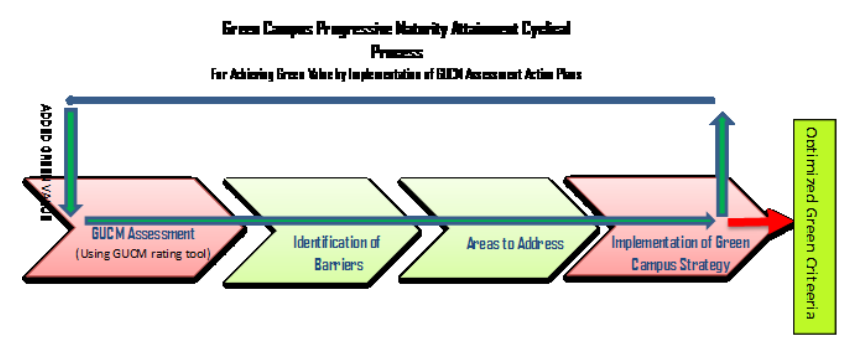

Fig. 3. GUCM framework

\section{Conclusion}

This research can have a significant impact on universities and other related parties in Malaysia in attaining a higher level of awareness regarding the obstacles in implementing the green university campus concept. Additionally, this research outcome provides the basis on which to achieve more advanced level of sustainability through using this Green University Campus Maturity (GUCM) rating tool that is more specific for Malaysian universities.

By using the proposed GUCM framework, Malaysian universities can develop a strategy based on a more progressive approach towards sustainability. This green university campus attainment method allows one to target various levels of green campus maturity that is suitable to the individual context. Ultimately, by understanding there is recognition for minimum maturity level of green campus university categories, universities can work in a flexible manner to implement an adequate policy to achieve the green and sustainable concept based on their capabilities and constraints that are context specific within a progressive scope. 


\section{References}

1. K. K. Hooi, F. Hassan \& M. C. Mat, Procedia Soc. and Behv. Scs., 50 (July), 525-536, 2012.

2. CIDB. Construction Industry Transformation Programme (CITP) 2016-2020. Construction Industry Development Board Malaysia (CIDB, 2016).

3. H. M. Alshuwaikhat, I. Abubakar, J. Clean Prod., 16, 1777-1785, 2008.

4. R. Lozano, Int. J. of Sustbty. in Higher Edu., 12 (1), 67-78, 2011.

5. UNEP (2013). Greening Universities Toolkit. United Nations Environment Programme (UNEP Publishing Board, 2013).

6. S. Sala, B. Ciuffo, P. Nijkamp, Ecological Econs, 119, 314-325, 2015.

7. T. S. Grindsted, Env. Econs., 2(2), 29-36 (2011).

8. J. Mcmillin \& R. Dyball, J. of Edu for Sust Dvpmt, 3(1), 55-64 (2009).

9. R. Hussin, \& V. Kunjuraman, Msian. J. of Soc. and Space 11(3), 84-96 (2015).

10. N. Suwartha \& R. F. Sari, (2013). J. of Cleaner Prod., 61, 46-53 (2013).

11. S.N.N. Syed Yahya, A.R.M. Ariffin, M. A. Ismail, Green Buildings in Campus: An Assessment of Green Potential for Existing Conventional Buildings (2018) [Online]. Available: file://D:/Downloads/Mar10141RCCS2014SABAH-FullPaper-plaintext.pdf

12. N. S. H. Rahimy. UPM is top eco-friendly varsity in Malaysia - Nation (2016) [Online]. Available: | The Star Online. http://www.thestar.com.my/news/nation/2016/01/2 6/upm-is-top-ecofriendly-varsity-in-malaysia.

[Accessed March 5, 2017]

13. L. Velazquez, N. Munguia, A. Platt \& J, J. of Cleaner Prod., 14(9-11), 810-819 (2006).

14. UI GreenMetric World University Rankings 2017. Global Partnerships for a Sustainable Future (2017). [Online]. Available: http://greenmetric.ui.ac.id/wp content/uploads/2015/07/UI-GreenMetricGuideline-2017_ENG.pdf

15. STARS AASHE. STARS 2.1 credit checklist (2018). [Online]. Available: https://docs.google.com/spreadsheets/d/19mT7ibiJ4 cm0Ng6BsIRIDldYbyzIEdb45fAR7hi3f2c/edit\#gid $=0$.

16. AASHE. STARS technical manual version 2.1, administrative update 2 (2017). [Online]. Available: $\quad \mathrm{http}: / / \mathrm{www}$. aashe.org/wpcontent/uploads/2017/04/STARS-TechnicalManual-v2.1.2.pdf.

17. Green Building Index Sdn Bhd. Green Building Index. (Vol. 238, pp. 1-6) (2014). [Online]. Available: http://new.greenbuildingindex.org/

18. R. Rahardjati, M. F. Khamidi \& A. Idrus, Proc. of the 2nd Int. Conf. on Env. Sc. and Tech., ICEST, 6, 148-151 (2011).
19. L. Velazquez, N. Munguia, \& M. Sanchez. Int. J. of Sust. in Higher Edu. 6(4), 383-391 (2005).

20. A. J. Hoffman, (2008). Overcoming the Social and Green Building. Org. \& Env., 390-419.

21. Z. Xiaolu, Org, Tech. and Mgmt. in Const.: An Int. Jnl., 6(3), 1134-1140 (2014).

22. E. A. Hopkins. Smart and Sustainable Built Environment, 5 (4) 340-351 (2014). 